\title{
Application of Controlling Instruments for Improvements in Cow Sire Selection
}

\author{
S. König, ${ }^{1}$ S. Lessner, and H. Simianer \\ Institute of Animal Breeding and Genetics, University of Göttingen, 37075 Göttingen, Germany
}

\begin{abstract}
National estimated breeding values of bulls from 1998 through 2006 from 12 different German artificial insemination (AI) organizations were used to determine the differences in expected and realized selection intensities for cow sire selection, considering the total merit index as well as subindexes for production, conformation, somatic cell count, fertility, and functional herd life. The expected selection intensity was derived from a Gaussian distribution and from the replacement rate describing the percentage of bulls graduated as cow sires from the total amount of progeny-tested young bulls within the AI organization and by birth year. Realized selection intensities for all indexes were derived from the selection differential of cow sires, defined as the deviation of the average index of selected cow sires from the average index of the total number of progenytested young bulls. A low replacement rate of cow sires was associated with relatively high realized selection intensities for the total merit, production, and conformation indexes, but was not related to the somatic cell count, fertility, and functional herd life indexes. The controlling value, defined as the ratio of realized to expected selection intensities, indicates the effectiveness of cow sire selection for different traits. Low controlling values (i.e., low realized selection intensities in combination with moderate or high expected selection intensities) suggest improvements in the step of cow sire selection, especially when discussing the total merit index. Analysis of variance revealed significant differences in expected selection intensities, realized selection intensities, and controlling values for the total merit, production, and conformation indexes between AI organizations and birth years of bulls. Artificial insemination organizations applying well-defined breeding policies (e.g., high controlling values for the total merit index) were successful in the national competition when evaluated according to the national top lists for
\end{abstract}

Received July 26, 2006.

Accepted December 4, 2006.

${ }^{1}$ Corresponding author: skoenig2@gwdg.de the respective indexes, regardless of the active population size. The suggested method also allows for comparison of the importance of different indexes in selection decisions. Furthermore, controlling values can monitor additional potential in the improvement of cow sire selection with respect to improvement of the genetic level in the whole population. The development of appropriate selection tools or controlling instruments is of increasing concern for monitoring selection policies in the short term as well as for establishing sustainable breeding policies.

Key words: breeding program, selection intensity, controlling cow sire selection

\section{INTRODUCTION}

The availability of AI has led to breeding programs based on progeny testing (PT), as suggested by Henderson (1964) and Skjervold and Langholz (1964). Substantial genetic progress in production traits has resulted from conventional PT since the 1970s (e.g., Van Tassel and Van Vleck, 1991; Swalve and Höver, 2003), but some authors (e.g., Bolgiano et al., 1979; Van Vleck, 1987) have expected additional genetic gain because of improved selection strategies.

The design parameters that have attracted the most attention for optimizing PT have been the proportion of cows mated to young bulls, the number of young bulls progeny tested per year, and the number of daughters per young bull. For a given population size, the percentage of cows mated to young bulls and the number of daughters per young bull determine the number of young bulls to be progeny tested. During the last few decades, several papers have focused on optimizing these parameters (Skjervold and Langholz, 1964; Van Vleck, 1964; Oltenacu and Young, 1974; Dekkers et al., 1996). The optima for design parameters have varied widely among studies, depending on the objective. Including economic aspects, the optimal number of daughters per bull has been higher and the proportion of mating to young bulls has been reduced compared with studies whose objectives have focused only on the maximization of genetic gain. These recommendations concerning test capacities and economics, mostly based on 
results from Dekkers and Shook (1990) and Dekkers et al. (1996), have been implemented in dairy cattle breeding programs in Germany.

Despite optimization of the number of bulls selected for PT, as well as the number of daughters per bull produced and the speed and accuracy of the PT, the net merit of bull sires and bull dams, and the intensity of selection after the test have mainly determined the rate of genetic gain. Selection of superior bulls accounts for 70 to $76 \%$ of the total genetic gain that is possible in the dairy cattle population (Robertson and Rendel, 1950; Van Vleck and Murphy, 1983). Bull sires generate test bulls, and their selection is one important tool in dairy cattle breeding programs regarding the level of inbreeding and relationships among animals, as well as the genetic merit in future generations (König and Simianer, 2006). However, selection of superior cow sires (CS) for AI among the total pool of young bulls has also drawn the attention of AI organizations. An evaluation of the annual statistics of the German Cattle Breeders' Federation (ADR, 2004) showed that $60 \%$ of the inseminations of cows were made with CS stemming from the organization's own PT program. Based on this high proportion, CS selected out of the pool of preselected young bulls have an essential, direct impact on the phenotypic performance and also on the EBV of cows. Optimization and control of selection intensities for the most important traits following PT will be a crucial part of future dairy cattle breeding programs. Swalve and Höver (2003) analyzed genetic trends for production traits of cows within 4 distinct regions of Germany and suggested additional genetic gain when focusing breeding objectives on a selection index closely related to the German total merit index (RZG). Following Swalve and Höver (2003) and the annual statistics published for AI (ADR, 2004), CS selection practiced by AI organizations not only depends on their total merit index, but is determined by traits such as direct calving ease or direct stillbirth increasing the market share for a short period. In the long term, the success of AI organizations and the accumulation of genetic gain will strongly depend on selection of superior sires according to their RZG, which combines all traits based on their genetic parameters and economic importance.

In this study, data on national breeding values over a period of $8 \mathrm{yr}$ were used to compare selection policies for different traits and in different breeding programs. Evaluation of the realized selection intensities of CS in the most relevant indexes and comparison with expected possibilities, defined in this study as controlling values, can be a powerful instrument to verify selection decisions and eventually explain pronounced differences in the success of AI organizations.

\section{MATERIALS AND METHODS}

Data were the German RZG, production index (RZM), conformation index (RZE), SCC index (RZS), reproduction index (RZZ), and functional herd life index (RZN) of Holstein bulls from EBV databases from August 1998 through February 2006 from 12 different AI organizations located in Germany. In Germany, all indexes are expressed as relative breeding values, standardized to a yearly rolling base with a mean of 100 points and a standard deviation of 12 points. The relative weights of the subindexes RZM, RZE, RZS, RZZ, and RZN in the overall index RZG are 50, 15, 5, 5, and $25 \%$, respectively. The RZM includes fat kilograms and protein kilograms in a ratio of 1:4. Estimated breeding values of 18 linear conformation traits and $4 \mathrm{EBV}$ for general characteristics (angularity; body, feet, and legs; and udder) are combined in the total composites for dairy type; body, feet, and legs; and udder. The 4 total composites are then combined into a subindex for a total conformation called RZE. The reproduction subindex (RZZ) is defined as an index combining the direct and maternal EBV for calving ease, stillbirth, and nonreturn rate. The solutions from the genetic evaluation of length of productive life are combined in the RZN subindex with evaluations of auxiliary traits (i.e., predictors of longevity) through selection index calculations.

The decision of an AI organization to return a bull to service (cow sire for AI) or to cull the bull is generally made at the time of his first appearance in the quarterannual data file (EBV-1) for national genetic evaluation, having a reliability of at least 0.70 for production traits. Later evaluations (EBV-2) are analyzed to identify whether the sire has had second-crop daughters, because EBV based on daughters from graduated sires are marked in the data file and are therefore distinguishable from EBV based only on PT. A bull is identified in the data file for second-crop daughters when at least 5 additional daughters with test-day records $7 \mathrm{yr}$ after the birth of the bull are available. Because of the time lag between EBV-1 and EBV-2, the study is restricted to historical data encompassing bulls of the birth years between 1992 and 1996. As an example, for 2 bulls born in December 1992 and December 1996, Table 1 characterizes the main events in the bulls' lifetimes, which are essential for the method applied. A similar method for evaluating international EBV and to identify differences in breeding objectives across countries was used by Powell et al. (2003).

Realized selection intensities $\left[\mathbf{i}_{\mathbf{r}(\mathbf{j})}\right]$ for CS in the indexes for RZG, RZM, RZE, RZS, RZZ, and RZN were calculated as follows: 
Table 1. Stations in life (mo/yr) of sires born in 12/1992 and 12/1996: From birth until breeding value estimation based on second-crop daughters ${ }^{1}$

\begin{tabular}{|c|c|c|c|c|c|c|c|c|}
\hline \multirow[b]{2}{*}{ Birth } & \multicolumn{5}{|c|}{ Information based on PT } & \multicolumn{3}{|c|}{ Graduated cow sire } \\
\hline & $\begin{array}{c}\text { Start of } \\
\text { PT }\end{array}$ & $\begin{array}{c}\text { End of } \\
\text { PT }\end{array}$ & $\begin{array}{c}\text { Birth of } \\
\text { calves }\end{array}$ & $\begin{array}{l}\text { Calving of } \\
\text { daughters }\end{array}$ & EBV-1 & $\begin{array}{l}\text { Birth of } \\
\text { calves }\end{array}$ & $\begin{array}{l}\text { Calving of } \\
\text { daughters }\end{array}$ & EBV-2 \\
\hline $12 / 1992$ & 05/1994 & 09/1994 & 06/1995 & $12 / 1997$ & 08/1998 & 04/1999 & $10 / 2001$ & $02 / 2002$ \\
\hline $12 / 1996$ & $05 / 1998$ & 09/1998 & 06/1999 & $12 / 2001$ & $08 / 2002$ & $04 / 2003$ & $10 / 2005$ & $02 / 2006$ \\
\hline
\end{tabular}

${ }^{1} \mathrm{EBV}-1$ = decision of cow sire selection (graduating or culling) and station of life when calculating pedigree indexes; EBV-2 = database of estimated breeding values for the applied method for verification of culling or graduating at EBV-1; PT = progeny testing.

$$
\mathrm{i}_{\mathrm{r}(\mathrm{j})}=\frac{\mu_{\text {index }_{(\mathrm{j})}-\mathrm{CS}}-\mu_{\text {index }_{(\mathrm{j})}-\mathrm{PT}}}{\sigma_{\text {index }_{(\mathrm{j})}}}
$$

where $\mu_{\text {index }}$ CS is the average index of selected CS within an AI organization and birth year at EBV-1, $\mu_{\text {index }-\mathrm{PT}}$ is the average index of all progeny-tested bulls from the same AI organization and birth year at EBV1 , and $\sigma_{\text {index }}$ is the respective standard deviation. The subscript $j$ indicates the different indexes. The expected selection intensity $\left(\mathbf{i}_{\mathbf{e}}\right)$ was derived from the Gaussian distribution and the replacement rate. This indicates that $i_{\mathrm{e}}$ is equal for all indexes within birth year and AI organization, whereas $i_{r(j)}$ depends on the different indexes, $\mathrm{j}$. The replacement rate describes the percentage of bulls graduated as CS from the total number of progeny-tested young bulls within an AI organization and birth year. A more stringent selection of CS increases the expected selection intensity and should increase the realized selection intensity in most important indexes, assuming the graduation of superior bulls according to their total merit index. Table 2 gives an overview of test capacities, replacements, and expected selection intensities stratified by AI organizations and averaged over the birth years of bulls. Re- placement rates of CS varied highly among $\mathrm{AI}$ organizations and were extremely low and constant for organizations $\mathrm{E}$ and $\mathrm{K}$, showing values of 8.4 and $8.5 \%$ for replacements with standard deviations of only 2.1 and 1.1, respectively. In AI organization $\mathrm{D}$, a less stringent selection was applied. Over one-quarter (26.4\%) of all bulls were graduated as CS in the birth years from 1992 to 1996.

Four different analyses of practical relevance are given in Table 3, comparing $i_{r(j)}$, $i_{e}$, or a combination of both. First, results for $i_{r(j)}$ across the different trait complexes allow comparison of the relevance of traits for selecting CS over time. Second, the comparison of $i_{r(j)}$ across AI organizations can provide hints for improving the current CS selection decisions. Third, low values for $i_{e}$ suggest decreasing the replacement rate of CS to increase the genetic level in the population through a restricted selection of superior sires. And last and most important, low values for $i_{r(j)}$ in combination with moderate or high values for $i_{\mathrm{e}}$ suggest focusing selection more on the respective index, especially when discussing the total merit index. This last case emphasizes the magnitude of one essential controlling instrument in practical dairy cattle breeding programs: the compar-

Table 2. Number of young bulls (test capacity), replacement rates (p, in \%) and expected selection intensities $\left(i_{\mathrm{e}}\right)$ for cow sires stratified by AI organizations averaged over birth years of bulls from 1992 to 1996

\begin{tabular}{|c|c|c|c|c|c|c|}
\hline \multirow{2}{*}{$\begin{array}{l}\text { AI } \\
\text { organization }\end{array}$} & \multicolumn{2}{|c|}{ Test capacity } & \multicolumn{2}{|c|}{ Replacement rate } & \multicolumn{2}{|c|}{$\begin{array}{l}\text { Expected selection } \\
\text { intensity }\end{array}$} \\
\hline & Mean & $\mathrm{SD}$ & Mean & SD & Mean & SD \\
\hline A & 42.0 & 4.6 & 13.8 & 5.3 & 1.60 & 0.19 \\
\hline B & 22.6 & 2.2 & 14.0 & 6.1 & 1.59 & 0.22 \\
\hline $\mathrm{C}$ & 61.8 & 2.5 & 14.8 & 3.5 & 1.56 & 0.12 \\
\hline D & 61.6 & 5.4 & 26.4 & 8.5 & 1.24 & 0.20 \\
\hline $\mathrm{E}$ & 139.2 & 8.9 & 8.4 & 2.1 & 1.84 & 0.11 \\
\hline $\mathrm{F}$ & 53.8 & 2.5 & 18.8 & 9.2 & 1.43 & 0.25 \\
\hline G & 52.8 & 3.7 & 12.2 & 4.6 & 1.66 & 0.18 \\
\hline $\mathrm{H}$ & 118.2 & 4.5 & 8.2 & 2.8 & 1.85 & 0.09 \\
\hline I & 43.4 & 2.4 & 20.0 & 5.6 & 1.40 & 0.16 \\
\hline J & 40.2 & 2.8 & 16.1 & 6.2 & 1.52 & 0.21 \\
\hline K & 64.2 & 3.3 & 8.0 & 1.1 & 1.86 & 0.06 \\
\hline $\mathrm{L}$ & 42.2 & 4.6 & 10.6 & 3.1 & 1.73 & 0.13 \\
\hline Mean & 61.8 & 3.9 & 14.3 & 5.3 & 1.58 & 0.17 \\
\hline
\end{tabular}


Table 3. Steps for monitoring or controlling cow sire selection and interpreting results

\begin{tabular}{|c|c|c|}
\hline Step for monitoring or controlling ${ }^{1}$ & Indicator & $\begin{array}{l}\text { Practical relevance and suggestion } \\
\text { for the AI organization }\end{array}$ \\
\hline 1. Comparison of $i_{r(j)}$ over time & $\begin{array}{l}\text { Relevance of traits in cow sire selection } \\
\text { decisions over time }\end{array}$ & Verification of historical selection decisions \\
\hline 3. Analyses of $i_{e}$ & $\begin{array}{l}\text { Intensity of graduation of cow sires } \\
\text { (replacement rate) }\end{array}$ & $\begin{array}{l}\text { Low values of } i_{\mathrm{e}} \text { : } \\
\text { Stronger graduation of cow sires }\end{array}$ \\
\hline
\end{tabular}

${ }^{1} i_{r(j)}=$ realized selection intensity for index $j ; i_{e}=$ expected selection intensity; $c_{(j)}=$ controlling value for index $j$.

ison of realized values $\left[\mathrm{i}_{\mathrm{r}(\mathrm{j})}\right]$ in different indexes from the expected potential $\left(i_{\mathrm{e}}\right)$, defined as the controlling value,

$$
\operatorname{co}_{(j)}=\frac{i_{r(j)}}{i_{e}} .
$$

Low controlling values indicate an intensive graduation of CS (i.e., a small number of selected sires to produce second-crop daughters), but low realized selection intensity in the respective index $\mathrm{j}$. The realized selection intensity should be of the same dimension as the expected potential, especially for the most important index, the RZG. However, without including the preselection of young bulls in the analyses (e.g., the genetic merit of bull dams and bull sires), the suggested method might not allow for an optimal comparison of the importance of different indexes in selection decisions. An additional approximate calculation was done to derive the impact of indexes adjusted for preselection on $i_{r(j)}$ and $\mathrm{co}_{(\mathrm{j})}$. A pedigree index $\left[\mathbf{P I _ { ( j ) } ]}\right.$ for all traits and bulls, also standardized on a mean of 100 and a standard deviation of 12 points like the relative breeding values, was calculated considering indexes of sires and maternal grandsires (MGS) weighted by the coefficients of relationship as follows:

$$
\mathrm{PI}_{(\mathrm{j})}=0.5 \times\left[\operatorname{index}_{(\mathrm{j})}-\text { sire }\right]+0.25 \times\left[\operatorname{index}_{(\mathrm{j})}-\mathrm{MGS}\right]
$$

Pedigree indexes were also calculated for each bull at the time of his first appearance in the quarter-annual data file (Table 1) for national genetic evaluation, having a reliability of at least 0.70 for production traits. Ignoring indexes of bull dams when constructing the $\mathrm{PI}_{(\mathrm{j})}$ does not account for possible Mendelian sampling effects. On the other hand, potential biases in the results of the current study caused by preferential treatment of cows may have been avoided (Kuhn et al., 1994).

The adjustment of realized selection intensities was as follows:

$$
\mathrm{i}_{\mathrm{r}(\mathrm{j})} \text { adjusted }=\frac{\left(\mu_{\text {index }_{(\mathrm{j})}-\mathrm{CS}}-\mu_{\text {index }_{(\mathrm{j})}-\mathrm{PT}}\right)+\Delta \mathrm{PI}_{(\mathrm{j})}}{\sigma_{\text {index }_{(j)}}},
$$

with

$$
\Delta \mathrm{PI}_{(\mathrm{j})}=\mathrm{PI}_{(\mathrm{j})}-\left(\sum_{k=1}^{k=n} \mathrm{PI}_{(\mathrm{jk})}\right) / \mathrm{n}
$$

and $\mathrm{k}$ is the number of bulls within a given birth year. The adjustment procedure rewards a more intensive preselection and allows a more accurate comparison of the importance of different traits in selection decisions.

Analysis of variance was applied to identify the impact of birth years and AI organizations on $i_{e}, i_{r(j)}$, and $\mathrm{co}_{(j)}$. Beyond the overall mean effect and the random residual component, the statistical models included fixed effects of the AI organization and the birth year of the bulls.

In a second step, the impact of controlling values on the success of AI organizations was investigated for the different indexes. In Germany, the estimation of breeding values for the Holstein breed is centralized and results are ranked nationally, but the 12 different AI organizations operate regionally. This means that $\mathrm{PT}$ is performed within distinct regions and the main intention of $\mathrm{AI}$ organizations is to increase the number of their own bulls at the top of the common list for RZG. A success rate (SR) for AI stations stratified by the birth years of bulls was computed as follows:

$$
\mathrm{SR}_{(\mathrm{j})}=
$$

percentage of own bulls in a top list of $\mathrm{N}=100$ for trait $\mathrm{j}$ percentage of own bulls at the total test capacity

The higher the value for SR, the more successful was the respective AI organization. Analysis of variance, applying the MIXED procedure of SAS (SAS Institute, 1994), was used to identify the impact of several effects 


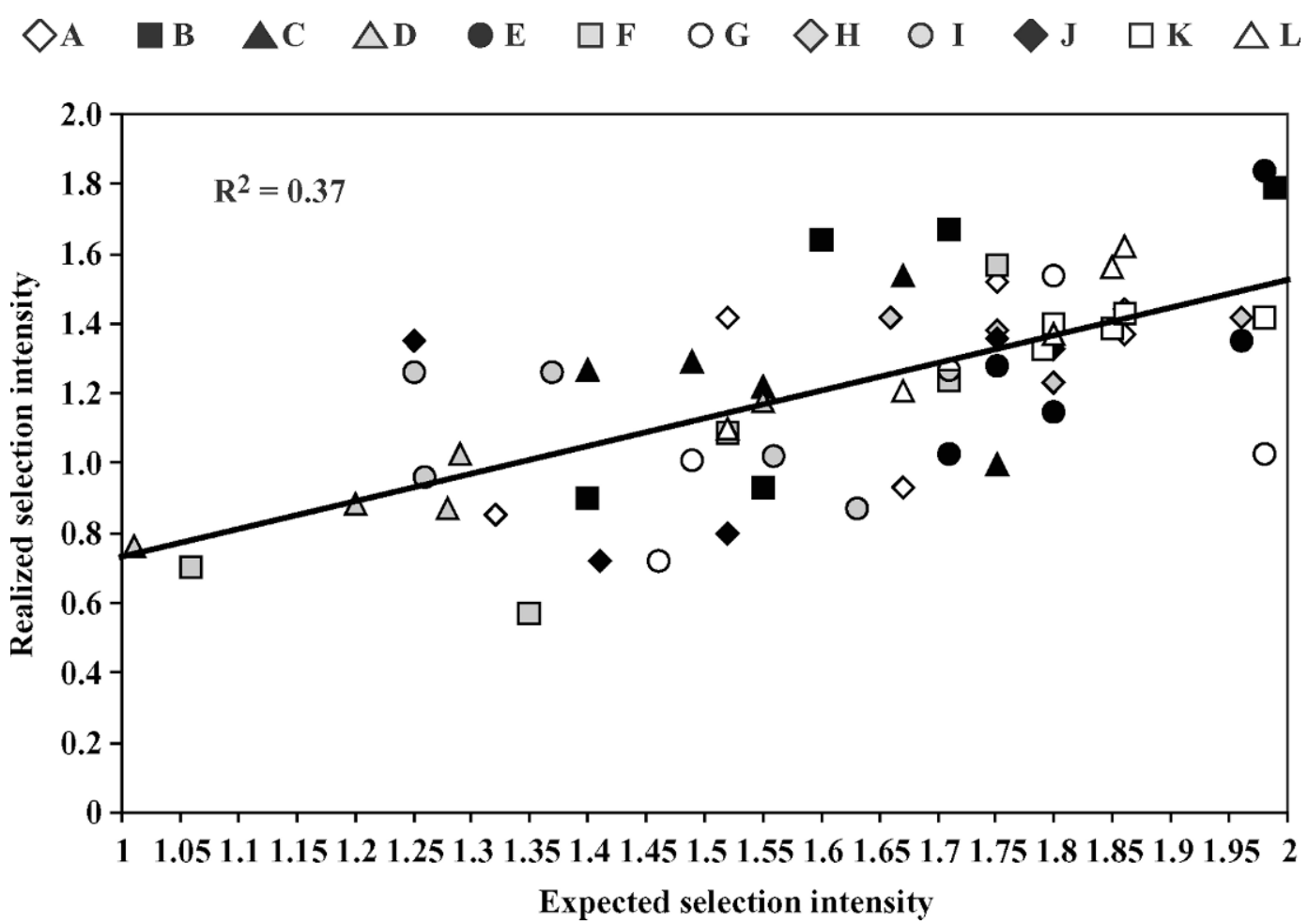

Figure 1. Realized selection intensities $\left[i_{r(R Z G)}\right]$ in dependency of expected selection intensities ( $i_{e}$ ) for 12 different AI organizations stratified by birth years of bulls from 1992 to 1996 for the total merit index (RZG). Different symbols denote different AI organizations (A to $\mathrm{L})$; solid line = linear regression of $\mathrm{i}_{\mathrm{r}(\mathrm{RZG})}$ on $\mathrm{i}_{\mathrm{e}}$.

on SR in RZG, RZM, RZE, RZS, RZZ, and RZN. The statistical model included the fixed effects of the birth year of bulls and the population size of the distinct AI region as well as a regression on controlling values up to the fourth polynomial degree to fit regression curves. Population size was divided into 3 classes: $\leq 100,000$ cows, from 100,001 to 150,000 cows, and $>150,000$ cows.

The nonsignificant regression coefficients of different polynomial structures were removed from the model by using $F$-statistic sum of square type I tests at $P<0.05$ rather than likelihood ratio tests. Based on type I sums of squares at $P<0.05$, a sequential analysis approach is appropriate for polynomial formulated models (Littel et al., 1999).

\section{RESULTS AND DISCUSSION}

\section{Realized Selection Intensities in Relation to Expected Selection Intensities}

Realized and expected selection intensities for AI organizations and different birth years of bulls are shown for RZG, RZM, RZE, RZS, RZZ, and RZN in Figures 1 to 6 , respectively. Each data point in the figures indicates a combination of $i_{r(j)}$ and $i_{e}$, where one AI organization and one birth year symbol was used. For RZG, RZM, and RZE, a pronounced dependency of $i_{r(j)}$ on $i_{e}$ was found, whereas realized selection intensities for the subindexes of functional traits (RZS, RZZ, and RZN) were not affected, or were less affected, by the expected potential. Regression coefficients for $i_{r(R Z G)}, i_{r(R Z M)}$, and $i_{r(R Z E)}$ in dependency of $i_{e}$ were 0.74 , 0.45 , and 0.89 , respectively, but were near zero for RZS (-0.01), for RZZ (0.04), and for RZN (0.06). These results indicate that the graduation of CS in Germany born between 1992 and 1996 was mainly based on RZG as well as on RZE and RZM. Intensive selection on RZG indirectly improved the selection intensities of RZM and RZE, and vice versa, because RZM and RZE had the highest impact on the total merit index (Rensing et al., 2002). In the middle and at the end of the 1990 s, the weights for RZS, RZZ, and RZN in the total merit index were only 14,4 , and $6 \%$, respectively, which encouraged AI stations to select on indexes for production and conformation, regardless of the index for SCC or fertility. Because of the negative correlations or correlations near zero between production and so-called functional traits, as summarized by Thaller (1997), selection on production has led to slightly negative or negligible realized selection intensities for RZS and RZZ. 


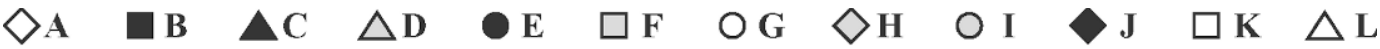

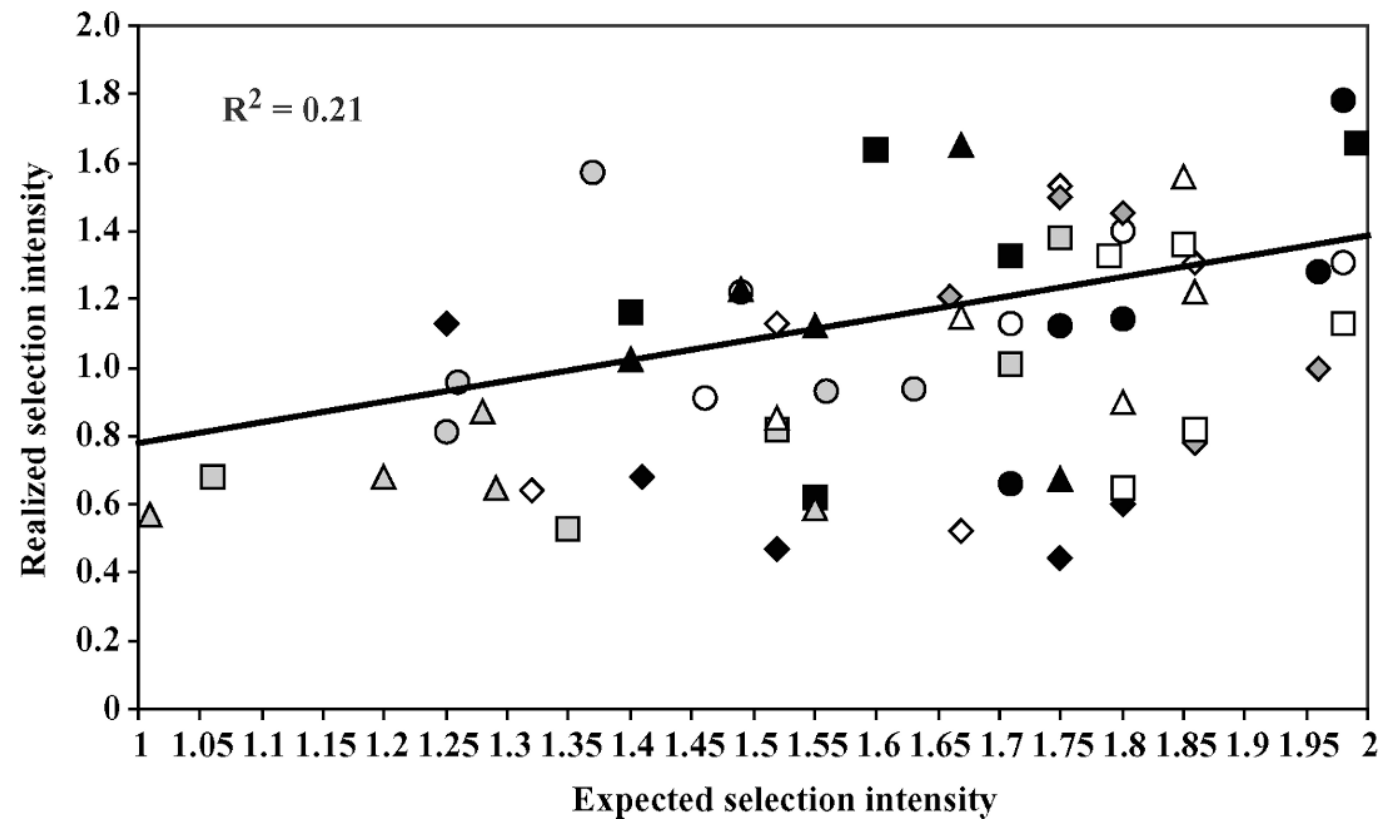

Figure 2. Realized selection intensities $\left[i_{r(R Z M)}\right]$ in dependency of expected selection intensities ( $i_{e}$ ) for 12 different AI organizations stratified by birth years of bulls from 1992 to 1996 for the production index (RZM). Different symbols denote different AI organizations (A to $\mathrm{L})$; solid line $=$ linear regression of $\mathrm{i}_{\mathrm{r}(\mathrm{RZM})}$ on $\mathrm{i}_{\mathrm{e}}$.

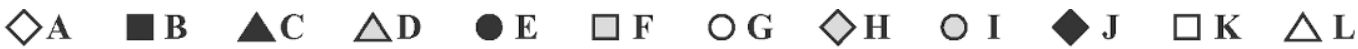

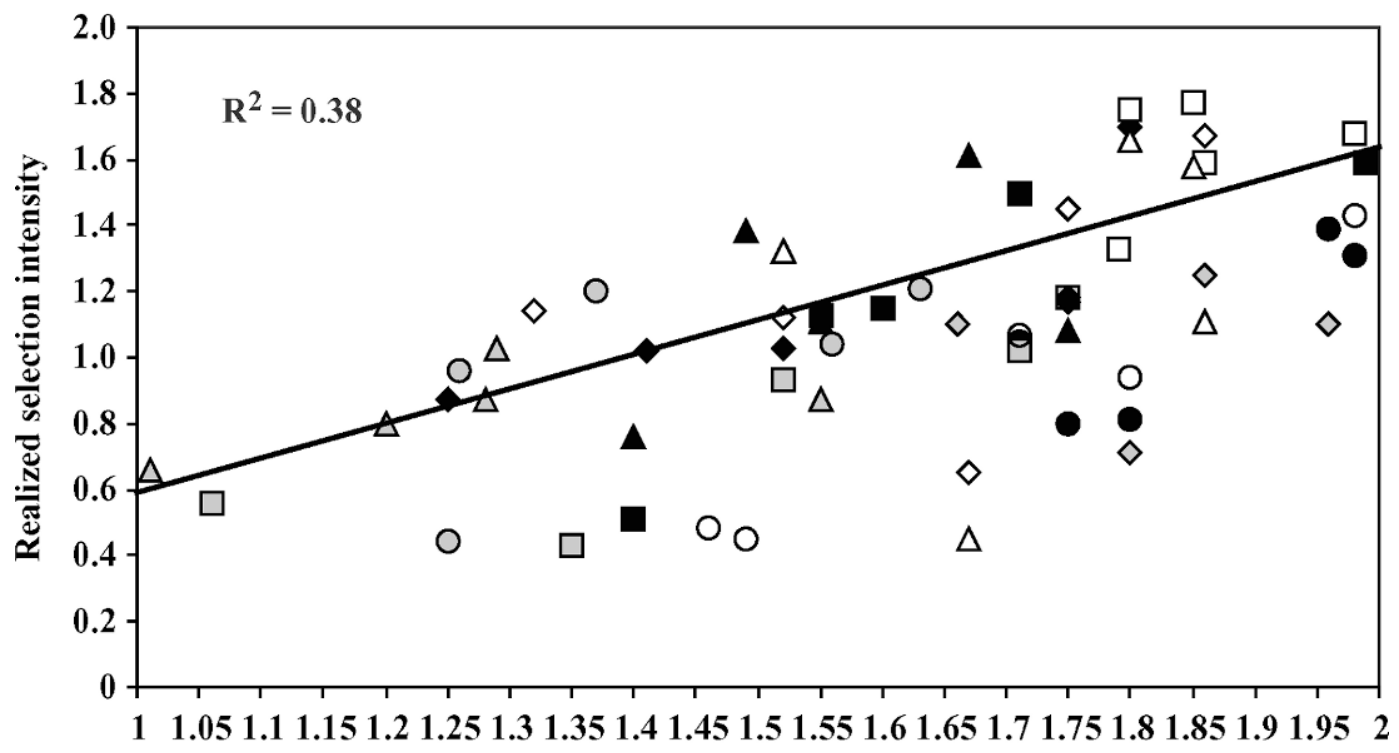

Expected selection intensity

Figure 3. Realized selection intensities $\left[i_{r(R Z E)}\right]$ in dependency of expected selection intensities $\left(i_{e}\right)$ for 12 different AI organizations stratified by birth years of bulls from 1992 to 1996 for the conformation index (RZE). Different symbols denote different AI organizations $($ A to $\mathrm{L})$; solid line = linear regression of $i_{\mathrm{r}(\mathrm{RZE})}$ on $\mathrm{i}_{\mathrm{e}}$. 
$\diamond \mathrm{A} \quad \square \mathrm{B} \quad \Delta \mathrm{C} \quad \triangle \mathrm{D} \quad \mathrm{E}_{\mathrm{E}} \quad \square \mathrm{F} \quad \mathrm{OG}_{\mathrm{G}} \diamond_{\mathrm{H}} \quad \mathrm{OI}_{\mathrm{I}} \diamond \mathrm{J} \quad \square \mathrm{K} \quad \Delta \mathrm{L}$

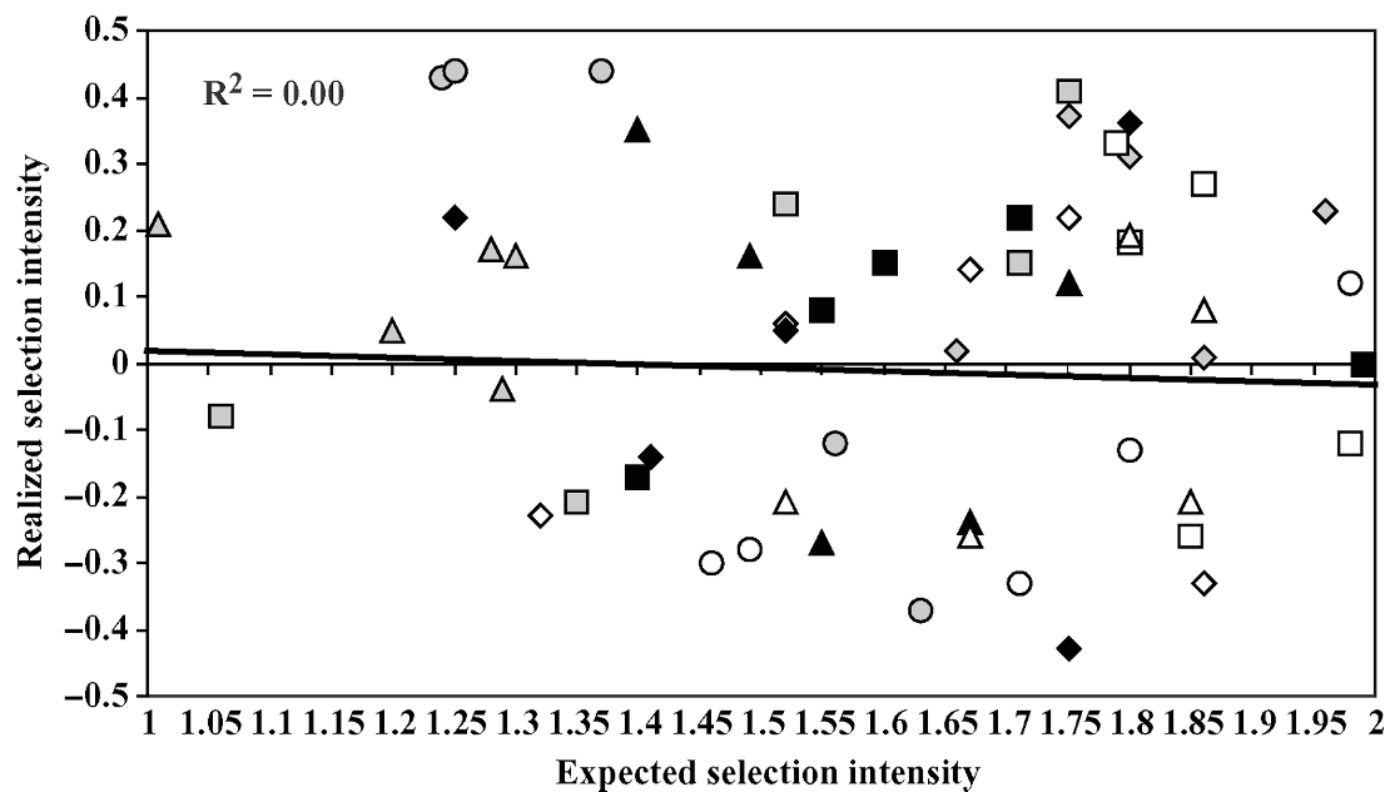

Figure 4. Realized selection intensities $\left[i_{r(R Z S)}\right]$ in dependency of expected selection intensities $\left(i_{\mathrm{e}}\right)$ for 12 different AI organizations stratified by birth years of bulls from 1992 to 1996 for the SCC index (RZS). Different symbols denote different AI organizations (A to L); solid line $=$ linear regression of $i_{\mathrm{r}(\mathrm{RZS})}$ on $\mathrm{i}_{\mathrm{e}}$.
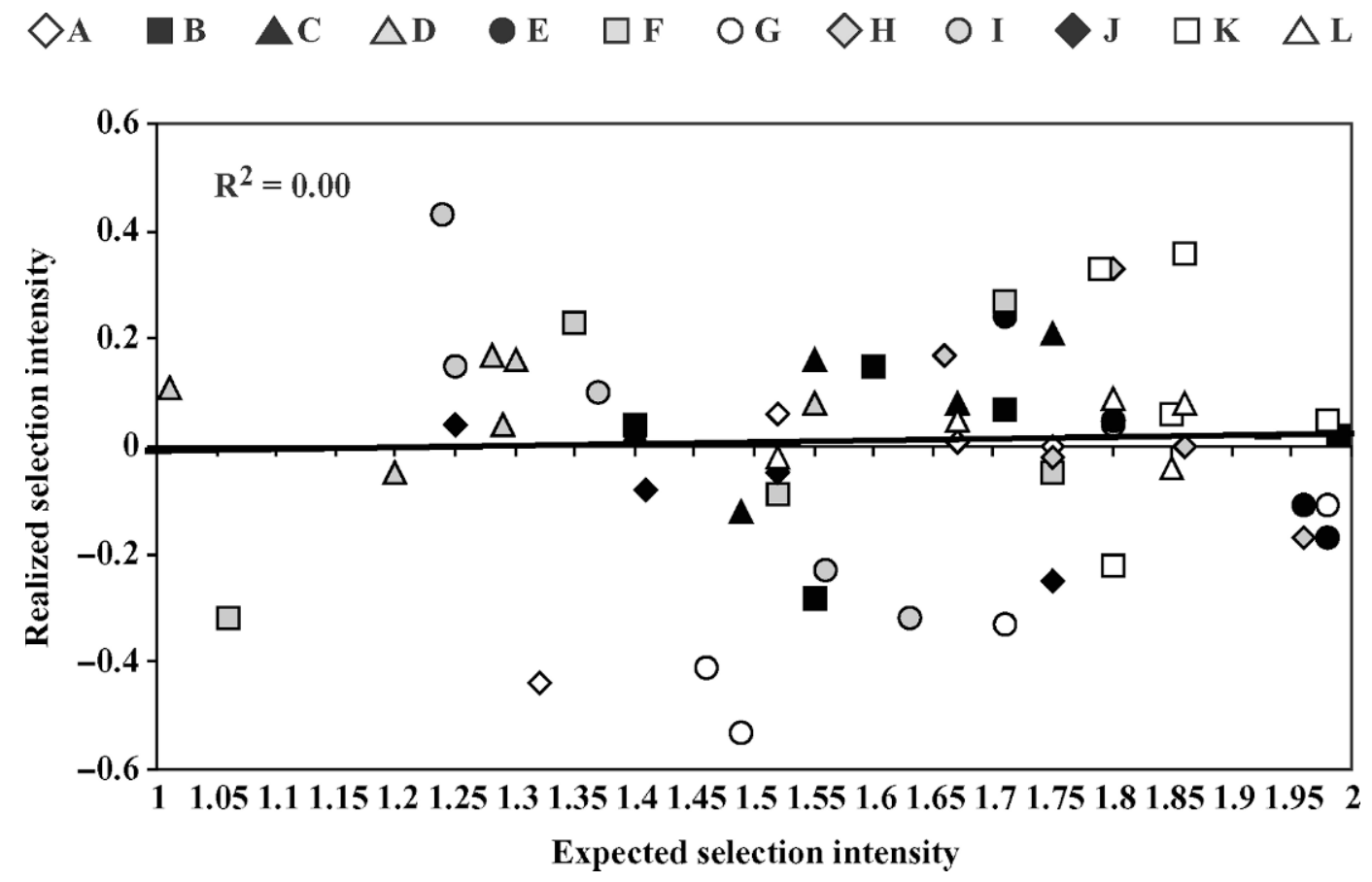

Figure 5. Realized selection intensities $\left[i_{r(R Z Z)}\right]$ in dependency of expected selection intensities $\left(i_{\mathrm{e}}\right)$ for 12 different AI organizations stratified by birth years of bulls from 1992 to 1996 for the fertility index (RZZ). Different symbols denote different AI organizations (A to $\mathrm{L})$; solid line $=$ linear regression of $i_{r(R Z Z)}$ on $i_{e}$. 

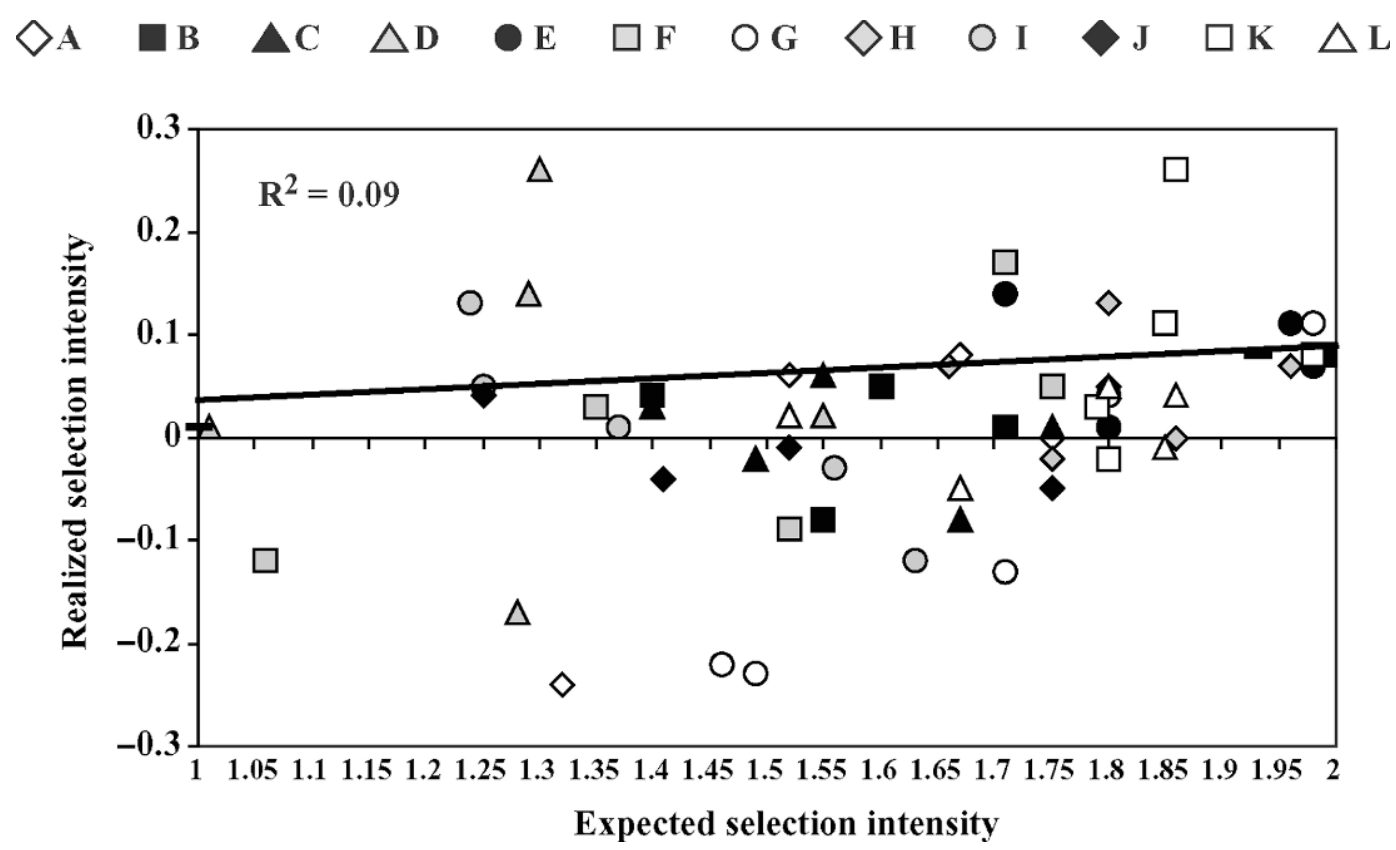

Figure 6. Realized selection intensities $\left[i_{r(R Z N)}\right]$ in dependency of expected selection intensities $\left(i_{e}\right)$ for 12 different AI organizations stratified by birth years of bulls from 1992 to 1996 for the functional herd life index (RZN). Different symbols denote different AI organizations (A to $\mathrm{L})$; solid line $=$ linear regression of $\mathrm{i}_{\mathrm{r}(\mathrm{RZN})}$ on $\mathrm{i}_{\mathrm{e}}$.

\section{Expected Selection Intensities}

Least squares means for expected selection intensities are shown in Table 4. A range from 1.25 to 1.86 for expected selection intensities indicates quite different breeding strategies among the German AI organizations. An expected selection intensity of 1.25 means that 1 of 4 young bulls was selected as a CS, whereas other AI organizations accomplished a more stringent selection program, applying replacement rates for CS of about $6 \%$. The ANOVA for $i_{\mathrm{e}}$ revealed pronounced significant effects of the AI organization $(P<0.001)$ and birth year of bulls $(P<0.01)$. Both effects together explained $67.9 \%$ of the total variation in $i_{e}$. Results

Table 4. Least squares means for expected selection intensities $\left(\mathrm{i}_{\mathrm{e}}\right)$, realized selection intensities $\left[\mathrm{i}_{\mathrm{r}(\mathrm{j})}\right]$, and controlling values $\left[\mathrm{co}_{(\mathrm{j})}\right]$ in indexes $\mathrm{j}=\mathrm{RZG}$, RZM, RZE, RZS, RZZ, and RZN for different AI organizations

\begin{tabular}{|c|c|c|c|c|c|c|c|c|c|c|c|c|c|}
\hline \multirow[b]{3}{*}{ AI organization } & \multirow[b]{3}{*}{$i_{e}$} & \multicolumn{12}{|c|}{ Index $^{1}$} \\
\hline & & \multicolumn{2}{|c|}{ RZG } & \multicolumn{2}{|c|}{ RZM } & \multicolumn{2}{|c|}{ RZE } & \multicolumn{2}{|c|}{ RZS } & \multicolumn{2}{|c|}{ RZZ } & \multicolumn{2}{|c|}{ RZN } \\
\hline & & $i_{r}$ & co & $i_{r}$ & co & $i_{r}$ & co & $\mathrm{i}_{\mathrm{r}}$ & co & $\mathrm{i}_{\mathrm{r}}$ & co & $i_{r}$ & co \\
\hline A & 1.58 & 1.14 & 0.72 & 0.94 & 0.59 & 1.13 & 0.72 & 0.03 & 0.01 & -0.11 & -0.07 & 0.11 & 0.07 \\
\hline B & 1.61 & 1.39 & 0.86 & 1.14 & 0.70 & 1.18 & 0.72 & 0.08 & 0.05 & -0.02 & -0.01 & 0.07 & 0.04 \\
\hline $\mathrm{C}$ & 1.57 & 1.25 & 0.80 & 1.15 & 0.73 & 1.19 & 0.75 & 0.02 & 0.02 & 0.07 & 0.04 & 0.08 & 0.05 \\
\hline D & 1.25 & 0.94 & 0.75 & 0.69 & 0.55 & 0.80 & 0.65 & 0.14 & 0.11 & 0.08 & 0.07 & -0.01 & -0.01 \\
\hline $\mathrm{E}$ & 1.84 & 1.33 & 0.72 & 1.20 & 0.64 & 1.07 & 0.58 & 0.03 & 0.02 & 0.01 & 0.01 & 0.09 & 0.05 \\
\hline $\mathrm{F}$ & 1.48 & 1.03 & 0.68 & 0.88 & 0.59 & 0.82 & 0.55 & 0.04 & 0.02 & 0.01 & -0.01 & 0.00 & 0.00 \\
\hline G & 1.69 & 1.11 & 0.66 & 1.19 & 0.71 & 0.87 & 0.50 & -0.07 & -0.05 & -0.27 & -0.17 & 0.01 & 0.01 \\
\hline $\mathrm{H}$ & 1.81 & 1.35 & 0.75 & 0.71 & 0.39 & 1.07 & 0.59 & 0.19 & 0.10 & 0.10 & 0.06 & 0.10 & 0.06 \\
\hline I & 1.41 & 1.07 & 0.78 & 1.05 & 0.75 & 0.93 & 0.67 & 0.18 & 0.15 & -0.05 & -0.02 & -0.02 & -0.01 \\
\hline J & 1.55 & 1.11 & 0.73 & 0.66 & 0.43 & 1.16 & 0.74 & -0.08 & -0.04 & -0.06 & -0.03 & -0.01 & -0.01 \\
\hline K & 1.86 & 1.39 & 0.75 & 0.99 & 0.52 & 1.58 & 0.85 & 0.17 & 0.09 & 0.02 & 0.01 & 0.09 & 0.05 \\
\hline $\mathrm{L}$ & 1.74 & 1.37 & 0.78 & 1.05 & 0.60 & 1.22 & 0.70 & 0.06 & 0.03 & 0.03 & 0.02 & 0.03 & 0.02 \\
\hline East & 1.54 & 1.20 & 0.78 & 1.04 & 0.68 & 1.03 & 0.67 & 0.09 & 0.06 & 0.04 & 0.03 & 0.06 & 0.04 \\
\hline West & 1.67 & 1.20 & 0.72 & 0.92 & 0.55 & 1.12 & 0.67 & 0.04 & 0.02 & -0.04 & -0.02 & 0.02 & 0.01 \\
\hline Mean & 1.62 & 1.20 & 0.75 & 0.97 & 0.62 & 1.09 & 0.67 & 0.07 & 0.04 & -0.01 & -0.01 & 0.04 & 0.02 \\
\hline
\end{tabular}

${ }^{1} \mathrm{RZG}$ = total merit index; RZM = production index; RZE = conformation index; RZS = SCC index; RZZ = fertility index; RZN = functional herd life index. 
Table 5. Least squares means for expected selection intensities $\left(i_{e}\right)$, realized selection intensities $\left[i_{r(j)}\right]$, and controlling values $\left[\mathrm{co}_{(\mathrm{j})}\right]$ in indexes $\mathrm{j}=\mathrm{RZG}$, RZM, RZE, RZS, RZZ, and RZN for different birth years of bulls

\begin{tabular}{|c|c|c|c|c|c|c|c|c|c|c|c|c|c|}
\hline \multirow[b]{3}{*}{ Birth year } & \multirow[b]{3}{*}{$\mathrm{i}_{\mathrm{e}}$} & \multicolumn{12}{|c|}{ Index $^{1}$} \\
\hline & & \multicolumn{2}{|c|}{ RZG } & \multicolumn{2}{|c|}{ RZM } & \multicolumn{2}{|c|}{ RZE } & \multicolumn{2}{|c|}{ RZS } & \multicolumn{2}{|c|}{ RZZ } & \multicolumn{2}{|c|}{ RZN } \\
\hline & & $i_{r}$ & co & $\mathrm{i}_{\mathrm{r}}$ & co & $\mathrm{i}_{\mathrm{r}}$ & co & $\mathrm{i}_{\mathrm{r}}$ & co & $i_{r}$ & co & $\mathrm{i}_{\mathrm{r}}$ & co \\
\hline 1992 & 1.48 & 1.01 & 0.68 & 0.93 & 0.63 & 0.93 & 0.63 & 0.13 & 0.07 & -0.01 & -0.01 & -0.02 & -0.01 \\
\hline 1993 & 1.57 & 1.11 & 0.71 & 0.86 & 0.55 & 0.94 & 0.58 & 0.01 & 0.02 & 0.04 & 0.03 & 0.06 & 0.04 \\
\hline 1994 & 1.58 & 1.20 & 0.76 & 0.88 & 0.57 & 0.96 & 0.61 & 0.13 & 0.09 & -0.01 & -0.01 & 0.05 & 0.03 \\
\hline 1995 & 1.67 & 1.29 & 0.76 & 0.91 & 0.55 & 1.26 & 0.76 & 0.02 & 0.01 & -0.07 & -0.04 & -0.03 & -0.02 \\
\hline 1996 & 1.77 & 1.39 & 0.79 & 1.27 & 0.72 & 1.34 & 0.76 & 0.05 & 0.03 & -0.02 & -0.01 & 0.07 & 0.04 \\
\hline Mean & 1.62 & 1.20 & 0.75 & 0.97 & 0.62 & 1.09 & 0.67 & 0.07 & 0.04 & -0.01 & -0.01 & 0.03 & 0.02 \\
\hline
\end{tabular}

${ }^{1} \mathrm{RZG}=$ total merit index; RZM = production index; RZE = conformation index; RZS = SCC index; RZZ = fertility index; RZN = functional herd life index.

indicate that expected selection intensities or replacement rates of CS were not random, but rather were determined by the breeding policy of the AI organizations (Table 4). Least squares means for $i_{e}$ indicated a more severe selection of CS in younger birth years (Table 5). Using Interbull data from 1995 through 2002, Powell et al. (2003) calculated a replacement rate of $15.8 \%\left(i_{e}=1.53\right)$ for German CS, which is close to the expected selection intensities found in this study for individual AI organizations. However, following the results of an international comparison, replacement rates for German CS are too high. In other influential countries for Holstein genetics (e.g., Canada, the Netherlands, or the United States), replacement rates for CS were in a range of 5.4 to $7.9 \%$ (Powell et al., 2003). A comparably intensive selection was practiced only within AI organizations $\mathrm{E}, \mathrm{H}, \mathrm{K}$, and $\mathrm{L}$. The relatively high percentage of bulls graduated in Germany could likely be influenced by the existence of several independent AI organizations, as suggested by Powell et al. (2003). A study of test capacities for young bulls across country borders (König et al., 2002) also revealed disadvantages for the German Holstein breeding program when focusing on the international comparison of size parameters. However, the size of the test capacity is not an inevitable reason for applying high replacements or low selection intensities and was not related to the success of German AI organizations (Grandke and Simianer, 1998).

\section{Realized Selection Intensities}

Analysis of variance revealed a significant impact $(P<0.05)$ of the fixed effects (AI organization and birth year of bulls) on $i_{\text {r(j) }}$ for the total merit index and indexes for production and conformation, respectively. Least squares means for $i_{r(R Z G)}, i_{r(R Z M)}$, and $i_{r(R Z E)}$ increased with the decreasing age of bulls but were in a nonsystematic order for RZS, RZZ, and RZN (Table
5). Realized selection intensities for all subindexes (Table 4) were within the range found in an international study conducted by Powell et al. (2003). Realized selection intensities for yield traits in their study tended to be around 1.0 for the overall data but ranged from 0.24 to 1.31 in different countries. Least squares means for $i_{\text {r(RZM) }}$ for different AI organizations within Germany varied from 0.66 to 1.20 (Table 4). Powell et al. (2003) expected the relatively low selection intensity for milk yield in the Netherlands because the total merit index in the Netherlands included a negative weight for milk (Miglior et al., 2005). Differences of $\mathrm{i}_{\mathrm{r}(\mathrm{j})}$ for AI organizations within Germany in the same year and for the same index cannot be explained by differences of weights in the total merit index. One reason could be that some German AI organizations have developed their own total merit index, deviating from the official RZG and especially adapting to the environmental effects and market conditions within their region. One example is the so-called Saxony Breeding Index (ZIS), which, for instance, has a higher emphasis on SCC compared with the RZG (Brade, 2004).

Low or even negative realized selection intensities in a range of -0.07 to 0.17 for RZS are of increasing concern with regard to the international trend and efforts to improve udder health in the cow population. A substantial improvement in such functional traits requires a special recording system, good data quality, appropriate statistical methods for the estimation of $\mathrm{EBV}$, and the willingness of AI organizations to change their breeding strategy toward more functionality. Such a system was successfully implemented in the Nordic countries (Heringstad et al., 2000). The advantage of the Nordic Holstein cattle population, when compared with populations in other countries for RZS (Simianer and König, 2002), justifies all efforts, such as the consequent selection on RZS for graduating CS in Sweden (Powell et al., 2003). 


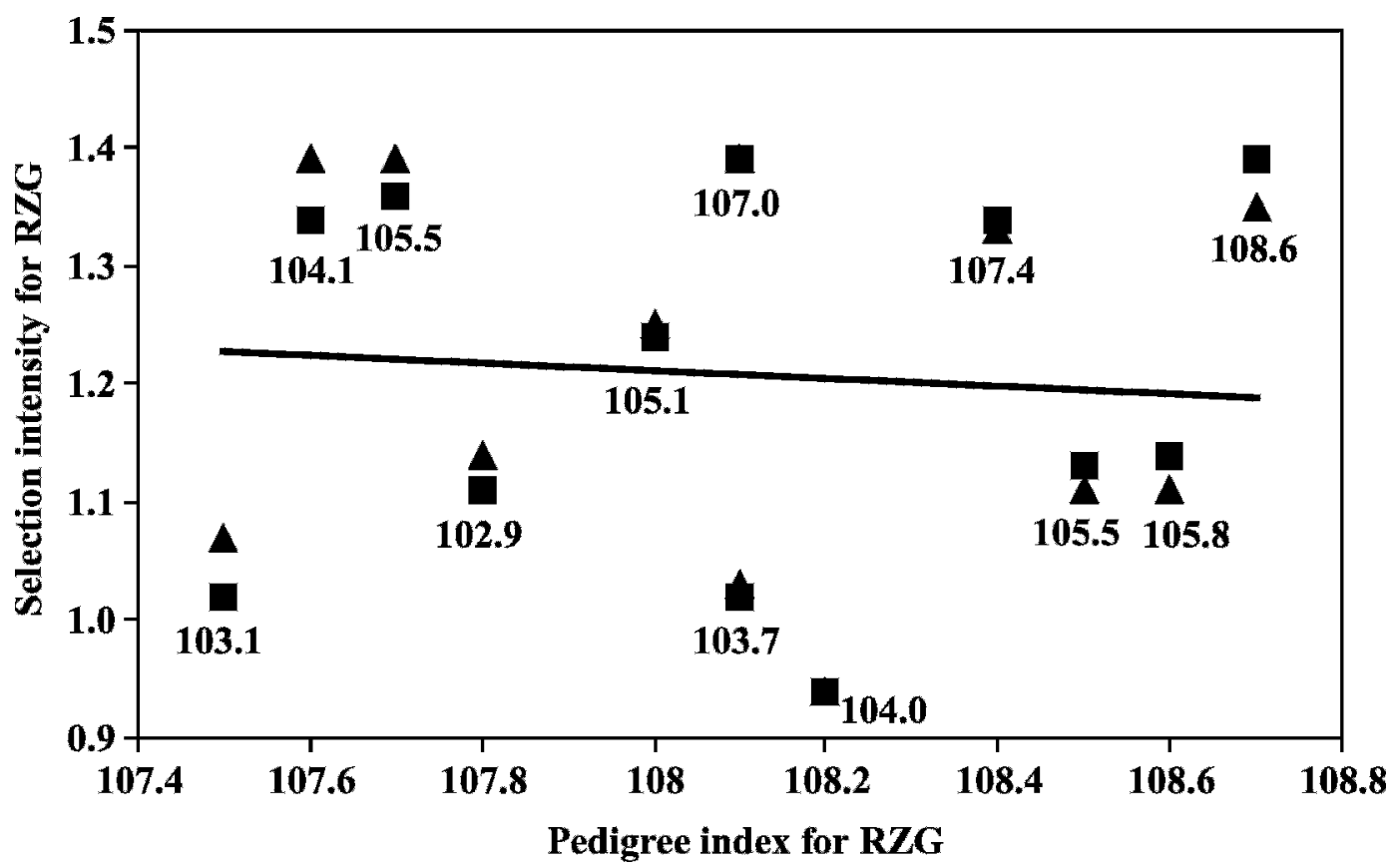

Figure 7. Realized selection intensity $\left[\mathrm{i}_{\mathrm{r}(\mathrm{RZG})} ; \mathbf{\square}\right]$ and for preselection adjusted realized selection intensity $\left[\mathrm{i}_{\mathrm{r}(\mathrm{RZG})}\right.$ adjusted; $\left.\mathbf{\Delta}\right]$ in dependency of the pedigree index for RZG $\left[\mathrm{PI}_{(\mathrm{RZG})}\right.$ ] for 12 different AI organizations. Solid line = linear regression of $\mathrm{i}_{\mathrm{r}(\mathrm{RZG})}$ on $\mathrm{PI}(\mathrm{RZG})$; figures below symbols denote average RZG of progeny test bulls in each AI organization.

The AI organizations B, C, D, E, and I belong to the former Eastern part and A, F, G, H, J, K, and L to the former Western part of Germany. Since the reunification of the 2 formerly separated German states in 1990, the German dairy cattle population has exhibited substantial heterogeneity in housing and management conditions. In Western Germany, small farms with herd sizes of around 30 to 100 cows are prevalent, whereas in Eastern Germany large-scale dairy farms with herd sizes of 500 to 2,000 cows are common. In addition to the heterogeneity of genetic parameters in the Eastern and Western parts of Germany (König et al., 2005), different selection strategies for CS can be anticipated because of the variation in environmental conditions. Least squares means for realized selection intensities of AI stations were averaged within the Eastern and Western states, respectively, and were higher for RZM, RZS, RZZ, and RZN in the Eastern part of Germany (Table 4). One can conclude that the production and functionality of cows is of greater importance in regions representing large-scale farms, compared with family farms in the Western part of Germany. Family farms are traditionally more interested in type components, as recently pointed out when analyzing the impact of conformation traits on auction prices of heifers (König et al., 2006). Average realized selection intensity for RZE was 1.12 in the Western part of Germany compared with $i_{\text {r(RZE) }}$ of 1.03 in the regions in Eastern Germany.

When discussing the importance of different traits based on $i_{r(j)}$ of CS, the influence of preselection (e.g., the genetic merit of bull dams and bull sires) should be evaluated. However, the $\mathrm{PI}_{(\mathrm{RZG})}$ of test bulls was relatively equal for all $\mathrm{AI}$ organizations, in the range of 107.8 to 108.7 , and was not affected by $i_{r(R Z G)}$, and vice versa (Figure 7). Selection of young bulls in German Holstein breeding programs has focused only on the same few sires per year. In addition, the maternal path of preselection is relatively equal, as pointed out by König and Simianer (2006). Selection of bull dams within and across country borders for German breeding programs is often done in cooperation with different AI organizations (König, 2001), keeping in mind the reduction in variable costs. Because of the minor impact of PI on the graduation of CS, differences between $i_{r(R Z G)}$ and $i_{r(R Z G)}$ adjusted were marginal (Figure 7). Comparing $i_{r(j)}$ and further, $\mathrm{co}_{(\mathrm{j})}$ without adjustments for preselection seemed to be a proper approach to monitor and control CS selection in dairy cattle breeding programs.

\section{Controlling Values}

Least squares means for the controlling values for different AI organizations are given in Table 4. A maxi- 
mal or optimal value of 1.0 indicates a stringent realized selection intensity, according to the expected guidelines derived from the replacement rate of CS. Least squares means for the controlling value were in the range of 0.39 to 0.85 for RZG, RZM, and RZE, respectively. Results revealed a much higher potential for the improvement of RZS, RZZ, and RZN. Partially negative controlling values were found for individual AI stations and birth years, obviously because of their minor impact on the total breeding goal. One can anticipate that the increase in weight for RZN in the total merit index from 6 to $25 \%$ should have positive effects on $i_{\mathrm{r}(\mathrm{RZN})}$ as well as on $\mathrm{co}_{(\mathrm{RZN})}$.

However, ANOVA also revealed significant $(P<0.05)$ fixed effects of AI organizations and the birth year of bulls on controlling values for RZG, RZM, and RZE, indicating a potential for improvement in realized selection intensities for some AI organizations without changing the replacement rate of CS. Analogous to the increased expected and realized selection intensities for younger bulls, higher controlling values were also found for RZG, RZM, and RZE in younger birth years (Table 5). Following the original ideas of animal breeding, it is strongly recommended that breeding strategies be oriented toward the total merit index (e.g., Beekman and Van Arendonk, 1993), assuming that weights for individual traits in a total merit index are derived correctly. Preliminary results of a current analysis conducted by Lind et al. (2006) for the derivation of economic weights in German dairy cattle underline the importance of higher weights for functional traits in the total merit index. Essential changes in the weights of individual traits in the RZG will have an impact on the realized selection strategies.

In conclusion, controlling values for RZG are the most important controlling instruments, and potential for the increase in $i_{r(R Z G)}$ and $\mathrm{co}_{(\mathrm{RZG})}$ was identified within several AI organizations. Because of the minor importance of functional traits in the total merit index (Rensing et al., 2002), one could expect that AI organizations applying less stringent selection intensities for RZG focus their breeding strategies on RZS, RZZ, or RZN, respectively. Such a hypothesis would suggest negative correlations between the controlling values for RZG and controlling values for functional traits, but correlations were near zero in our study. Some German AI organizations operate below their theoretical possibilities in all selection decisions, for the total merit index as well as for functional traits.

Van Tassel and Van Vleck (1991) concluded that the estimates of genetic selection differentials provide a measure of selection practices used historically and can help to determine the strengths and weaknesses in selection programs. Up to the 1990 s, the main breeding goal in dairy cattle around the world was milk production. In addition, from 1960 to 1990, Van Tassel and Van Vleck (1991) found much smaller realized selection differentials on the CS path than expected. Their results indicate that in the past, as well as in this study, selection of CS was consequently not focusing on the aggregate breeding goal. A clear potential exists for additional benefit to dairy cattle producers owing to improved selection strategies, because the maximum income at the farm gate level will be realized when selection is strongly oriented toward the total merit index.

Controlling values for all indexes except RZE were slightly higher in the Eastern part of Germany, compared with the regions located in the West (Table 4), mainly because of a lower $i_{e}(1.54$ vs. 1.67$)$ and higher $i_{r(R Z M)}, i_{r(R Z S)}, i_{r(R Z Z)}$, and $i_{r(R Z N)}$, respectively. Artificial insemination organizations from the Western regions are giving away more potential than their competitors in the East. They graduate a smaller percentage of sires, but several unimportant criteria seemed to be applied in selection decisions.

\section{SR}

The SR in dependency of the controlling value are depicted in Figure 8 for RZG, RZM, and RZE. For $\mathrm{SR}_{(\mathrm{RZG})}$, the regression on controlling values up to the third polynomial degree was significant $(P<0.05)$, whereas for RZM and RZE, only the linear term was considered in the statistical model. When analyzing the success of AI organizations in the top lists for RZS, RZZ, and RZN, neither fixed effects nor covariates of different polynomial structures were significant at $P$ $<0.05$. These results indicate that an intensive selection in most important traits toward the expected potential was the reason for the greater success of certain AI organizations (e.g., a higher number of their own bulls on the top list). Hence, well-defined breeding policies, such as the intensive selection of sires to produce second-crop daughters or an increase in PI, have positive effects on the presence of bulls on a top list and on their average total merit index. As shown in Figure 7 , a high $\mathrm{PI}_{(\mathrm{RZG})}$ in combination with high values for $i_{r(R Z G)}$ slightly increased the average RZG of young bulls within AI organizations.

According to the annual statistics of the German Cattle Breeders' Federation (ADR, 2004), 60\% of the inseminations of cows are made with CS originating from an organization's own region. Hence, intensively selected and genetically superior CS are mainly responsible for the average genetic level of the cow population and also for the genetic trend within the distinct AI region. These cows from an organization's own re- 


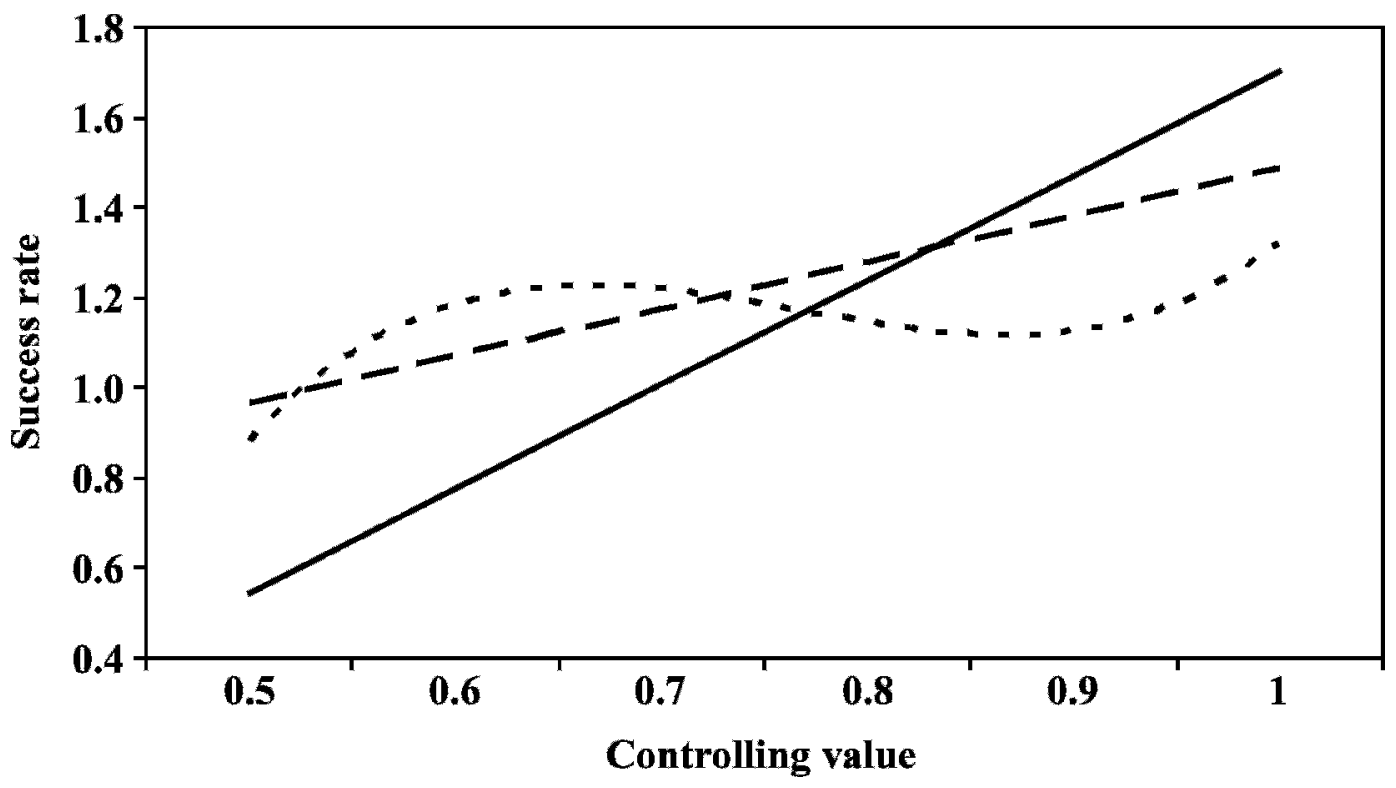

Figure 8. Least squares means for the success rate in the total merit index (RZG, dotted line), the production index (RZM, dashed line), and the conformation index (RZE, solid line) in dependency of controlling values for respective indexes.

gion are potential mating partners for the next generation of young bulls. A previous investigation conducted in the German Holstein population (König, 2001) showed that regions characterized by a superior average genetic level for cows are more often present on the top lists of bulls. Details on or reasons for these findings should be analyzed in future studies.

The final impact of individual sires on the cow population may vary widely, depending on the selection decisions of dairy cattle farmers. If the replacement rate of CS for an AI organization is high and most inseminations were done with the best 2 or $3 \mathrm{CS}$ for RZG, no negative effect on the cow population could be expected. But the crucial points in each dairy cattle breeding program are the previous selection steps done by AI organizations. Dairy producers only have the possibility of selecting from the pool of preselected bull sires, and inappropriate selection decisions done by AI organizations are very difficult to compensate at the farm-gate level.

Following the results from this study, one practical recommendation for AI organizations to be successful in national and international competition is to increase the genetic level of the cows in the most important traits. As a first step, they have the possibility of increasing the selection intensities of CS originating from their own breeding programs. Second, and much faster, they can improve the genetic level of the whole population because of the increase in AI from superior bulls from other regions or from foreign countries. Such a method implies the willingness of milk produc- ers to inseminate their cows using foreign bulls, but the percentage of these bulls used for AI is actually below $10 \%$. In addition, exchange of semen from superior sires among different regions within Germany is limited to $15 \%$ (ADR, 2004).

Breeding plans developed at the beginning of AI in Germany (e.g., Skjervold and Langholz, 1964; Lindhe, 1968; Langholz, 1970) have shown a pronounced dependency of genetic gain on the population size. These findings could be of practical relevance when considering populations of fewer than 10,000 cows, but current German breeding programs consist of at least 50,000 cows. Swalve and Höver (2003) compared the genetic trends within 4 different regions of Germany, but marginal differences in annual changes of EBV were independent of the population size.

Population size seemed to be an unsuitable parameter when evaluating the success of AI organizations (e.g., counting the number of bulls in a common top list), as pointed out by Grandke and Simianer (1998) and confirmed in the current study. Analysis of variance revealed no significant impact $(P<0.05)$ of the population size on SR. On the contrary, the opposite trend was found. Least squares means for SR in RZG were slightly higher for smaller populations of fewer than 50,000 cows and in a nondirectional order for RZM and RZE, respectively (Figure 9). The lowest success rates for all EBV were found for AI organizations representing a medium-sized population of 50,000 to 100,000 cows. 


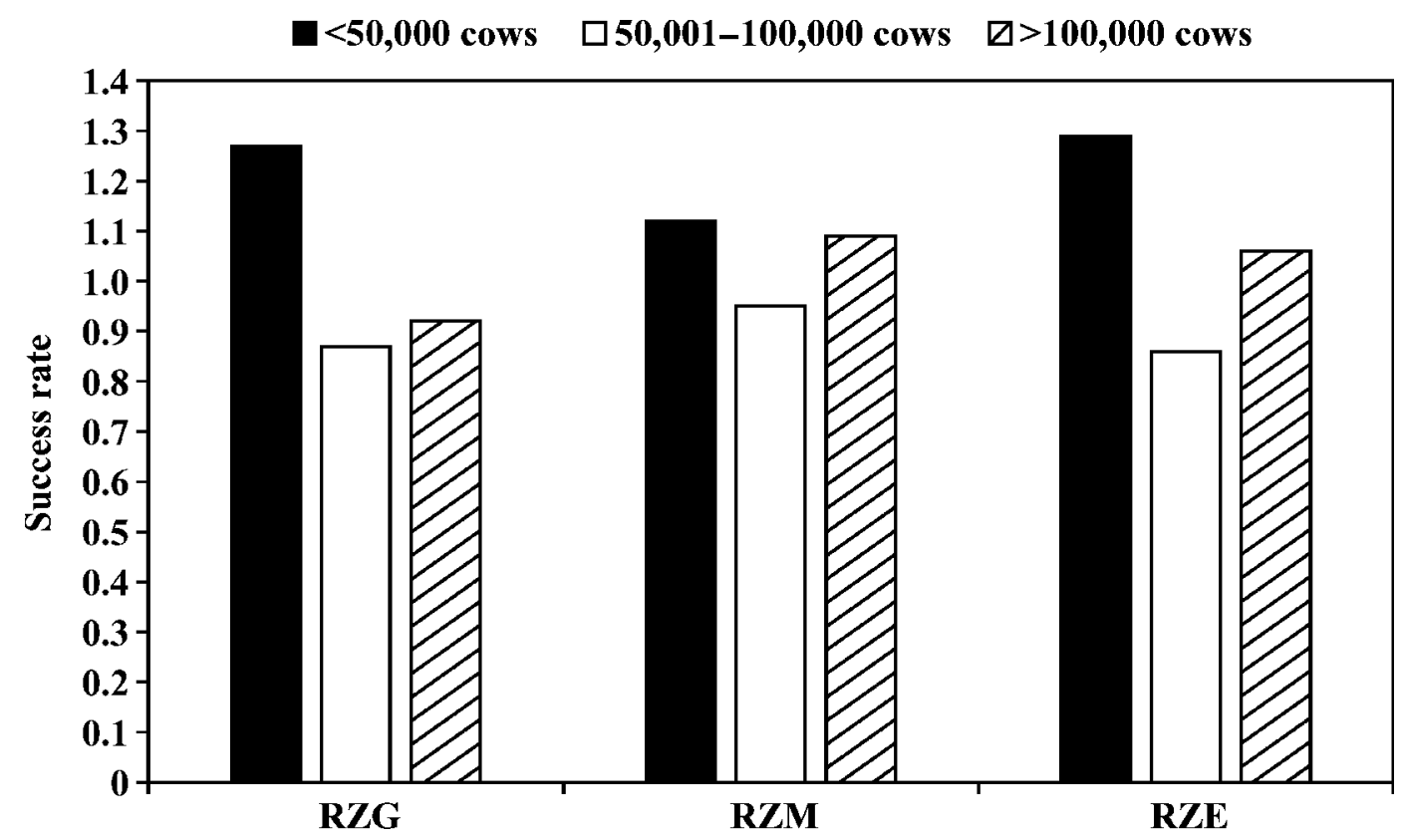

Figure 9. Least squares means for the success rate in the total merit index (RZG), the production index (RZM), and the conformation index (RZE) for 3 different classes of population size.

One successful AI organization belonging to the group with fewer than 50,000 cows has implemented several additional tools, such as the use of multiple ovulation and embryo transfer (MOET) breeding programs and a centralized test of bull dams on station (Swalve et al., 1993; König and Swalve, 2003) to increase the genetic level and to be successful among competitive AI organizations. The application of all available breeding tools (e.g., intensive selection of CS but also the establishment of a central station test of potential bull dams as well as the use of new reproductive technologies) can obviously compensate for disadvantages in scale. However, the objective of AI organizations is to develop proven bulls that are genetically superior to expand the market share of semen sales in national and international markets (Dekkers and Shook, 1990). After evaluating parameters influencing the success of PT programs, as pointed out by Dekkers et al. (1996) and Vierhout et al. (1998), no significant differences were found among German AI organizations (König, 2001). Size parameters, including the percentage of young bulls to be progeny tested per year or the numbers of daughters per bull, as well as the genetic merit of parents of bulls, were very similar.

Additional parameters must be defined and monitored for a breeding program to be successful in national and international competition. Selection strategies for CS according to the expected selection intensity in the total merit index indicate a well-organized breeding program. Artificial insemination organiza- tions operating in such a manner will carefully consider their breeding policies, will select superior sires in the most important traits for dairy producers, will increase the genetic merit of the cow population, and finally, will have more bulls on the national top list. Further consolidations of regional AI organizations toward larger, integrated national organizations force the development of controlling and monitoring instruments in several selection steps to evaluate and verify selection decisions. The method applied in this study documents the possibility and usefulness of controlling cow sire selection. For practical work of AI organizations, it is strongly recommended that a suitable database system based on current data be implemented to verify the steps in selection as early as possible.

\section{CONCLUSIONS}

The development of controlling instruments is of increasing concern in several fields of agriculture. In the case of dairy cattle breeding programs, controlling instruments are of particular importance for evaluating selection decisions in the short term as well as for instituting sustainable breeding policies. As shown in this study, parameters describing selection decisions for CS (e.g., realized and expected selection intensities as well as controlling values) varied widely among traits and German AI organizations. When evaluating national top lists of bulls for the most important indexes, the efficiency of selection was finally related to 
the success of the AI organizations. Furthermore, the controlling value indicated the presence of additional potential in the improvement of CS selection, which is essential for improving the genetic level of the whole population. The method applied here also allowed us to compare the importance of different subindexes in selection decisions of CS over a time span of several years. The consolidation of AI organizations and the incorporation of new traits and information sources, such as claw disorders or molecular data, make breeding policies more complex and difficult. Other tasks beyond maximization of the total merit index, such as controlling inbreeding, will also play an important role in future dairy cattle breeding programs. Guidelines for optimal selection should be developed and evaluated at defined intervals. Practical selection based on such guidelines or controlling values will ensure more efficiency, or at least minimize errors, in the practical breeding program. The presence of bulls on top lists for indexes determining the market share can even be increased when applying well-defined controlling parameters, as shown in this study.

\section{ACKNOWLEDGMENT}

The authors thank the VIT (Verden, Germany) for providing the quarter-annual national EBV databases since August 1998.

\section{REFERENCES}

ADR (Arbeitsgemeinschaft Deutscher Rinderzüchter). 2004. Annual statistics published by the German Cattle Breeders Federation. ADR, Bonn, Germany.

Beekman, H., and J. A. M. Van Arendonk. 1993. Derivation of economic values for veal, beef and milk production using profit equations. Livest. Prod. Sci. 34:35-56.

Bolgiano, D. C., L. D. Van Vleck, and R. W. Everett. 1979. Fluctuation in sire evaluations. J. Dairy Sci. 73:1902-1923.

Brade, E. 2004. Züchterische Schwerpunkte der Milchrindzucht in Sachsen. DGfZ-Schriftenreihe 34:49-58.

Dekkers, J. C. M., and G. E. Shook. 1990. Economic evaluation of alternative breeding programs for commercial artificial insemination firms. J. Dairy Sci. 73:1902-1923.

Dekkers, J. C. M., G. E. Vandervoort, and E. B. Burnside. 1996. Optimal size of progeny groups for testing programs by artificial insemination firms. J. Dairy Sci. 79:2056-2070.

Grandke, R., and H. Simianer. 1998. An approach to quantify management differences between cattle breeding organisations. Arch. Anim. Breeding 41:143-150.

Henderson, C. R. 1964. Selecting the young sire to sample in artificial insemination. J. Dairy Sci. 47:439-441.

Heringstad, B., G. Klemetsdal, and J. Ruane. 2000. Selection for mastitis resistance in dairy cattle: A review with focus on the situation in the Nordic countries. Livest. Prod. Sci. 64:95-106.

König, S. 2001. Untersuchungen zu einem kooperativen Zuchtprogramm der Rasse Holstein Friesian. PhD Thesis University of Göttingen, Göttingen, Germany.

König, S., G. Dietl, I. Raeder, and H. H. Swalve. 2005. Genetic relationships between dairy performance under large-scale farm and family farm conditions. J. Dairy Sci. 88:4087-4096.
König, S., S. Schierenbeck, B. Lind, and H. Simianer. 2006. Breeding value for auction price-A total merit index in dairy cattle? Proc. 57th Annu. Mtg. Eur. Assoc. Anim. Prod., Antalya, Turkey. EAAP, Rome, Italy.

König, S., and H. Simianer. 2006. Approaches to the management of inbreeding and relationship in the German Holstein dairy cattle population. Livest. Sci. 103:40-53.

König, S., and H. H. Swalve. 2003. Optimum design of an on station test for potential bull dams. Proc. 54th Annu. Mtg. Eur. Assoc. Anim. Prod., Rome, Italy.

König, S., H. Täubert, H. Simianer, and H. H. Swalve. 2002. The Interbull Audit Project: Results of an international survey. Interbull Bull. 29:161-164.

Kuhn, M. T., P. J. Boettcher, and A. E. Freeman. 1994. Potential bias in transmitting abilities of females from preferential treatment. J. Dairy Sci. 77:2428-2437.

Langholz, H. J. 1970. Bestimmungsmomente der Zuchtplanung beim Rind in Niedersachsen. Züchtungskunde 42:454-463.

Lind, B., S. König, and H. Simianer. 2006. A multivariate approach to derive economic weights for production and functional traits in dairy cattle. Paper presented at the 57th Mtg. European Association for Animal Production, Anatalya, Turkey.

Lindhe, B. 1968. Model simulation of breeding within a dual purpose breed of cattle. Acta Scand. Agric. 18:33-39.

Littel, R., G. Milliken, W. Stroup, and R. Wolfinger. 1999. SAS System for Mixed Models. SAS Institute Inc., Cary, NC.

Miglior, F., B. L. Muir, and B. J. Van Doormal. 2005. Selection indices in Holstein cattle of various countries. J. Dairy Sci. 88:1255-1263.

Oltenacu, P. A., and C. W. Young. 1974. Genetic optimization of a young bull sampling program in dairy cattle. J. Dairy Sci. 57:894-897.

Powell, R. L., A. H. Sanders, and H. D. Normann. 2003. Progeny testing and selection intensity for Holstein bulls in different countries. J. Dairy Sci. 86:2614-2620.

Rensing, S., E. Pasman, F. Reinhardt, and E. Feddersen. 2002. New total merit index for Holsteins in Germany with more emphasis on herd life. Interbull Bull. 29:147-150.

Robertson, A., and J. M. Rendel. 1950. The use of progeny testing with artificial insemination in dairy cattle. J. Genet. 50:21-31.

SAS Institute. 1994. SAS/STAT Software: Changes and Enhancements. Release 6.10. SAS Institute Inc., Cary, NC.

Simianer, H., and S. König. 2002. Ist Zucht auf Krankheitsresistenz erfolgreich? Züchtungskunde 74:413-425.

Skjervold, H., and H. J. Langholz. 1964. Factors affecting the optimum structure of A.I. breeding in cattle. Z. Tierzuecht. Zuechtungsbiol. 80:25-40.

Swalve, H. H., and K. Höver. 2003. Examinations using the results of breeding value estimation for Holstein sires and cows in Germany. Arch. Anim. Breeding 46:113-126.

Swalve, H. H., H. Niermann, and P. Glodek. 1993. Genetic relationship between 1st lactation field performance and 2nd lactation test station records of potential bull dams. Arch. Anim. Breeding 36:3-11.

Thaller, G. 1997. Genetics and breeding for fertility. In Proc. Int. Workshop Genetic Improvement of Functional Traits in Cattle: Fertility and Reproduction. Interbull Bull. 18:55-61.

Van Tassel, C. P., and L. D. Van Vleck. 1991. Estimates of genetic selection differentials and generation intervals for four paths of selection. J. Dairy Sci. 74:1078-1086.

Van Vleck, L. D. 1964. Sampling the young sire in artificial insemination. J. Dairy Sci. 47:441-446.

Van Vleck, L. D. 1987. Selection when traits have different genetic gain and phenotypic variances in different environments. J. Dairy Sci. 46:983-987.

Van Vleck, L. D., and P. A. Murphy. 1983. Comparisons of dam's genetic evaluation on his sire's and his dam's genetic evaluation. J. Dairy Sci. 66:634-637.

Vierhout, C. N., B. G. Cassel, and R. E. Pearson. 1998. Influences of progeny test programs on genetic evaluations of young sires. J. Dairy Sci. 81:2524-2532. 